\title{
Una ética estructurista del carácter y la felicidad (Perfil zubiriano y aristotélico de la ética de Aranguren)
}

\author{
ADELA CORTINA
}

\section{Una tradición hispana}

«Los españoles - afirmaba José Ortega y Gasset en lúcida sentencia- hemos pasado de querer ser demasiado a demasiado no querer ser». Y llevaba razón en el diagnóstico de esa empecinada voluntad de anonimato, de la que forma parte el inveterado empeño de jamás valorar una tradición nacida y crecida en nuestro suelo, rumiada, escrita y leída en nuestro idioma. «iQue inventen ellos!» - sigue siendo la acomplejada máxima-. Que inventen ellos, que nosotros copiaremos, traduciremos, y nos cuidaremos muy mucho de aportar cosecha propia. Voluntad de nihilismo como cultura - sería el diagnóstico-, voluntad de «demasiado no querer ser". Una voluntad que, a Dios gracias, no han hecho suya algunos de nuestros filósofos; no ha hecho suya, en nuestro caso, José Luis Aranguren.

Ya en el comienzo de su Ética, en 1958, informaba al lector de que la obra tenía contraída una especial deuda con tres autores - Aristóteles, Santo Tomás y Zubiri-, si bien es cierto que a través de Zubiri entraba en escena el pensamiento de Heidegger, y que a todos ellos cabría añadir la figura de Ortega, e incluso la de Suárez. Sin embargo, un par de décadas más tarde reconocía sin empacho alguno su peculiar raigambre zubiriana. «Me considero zubiriano - declaraba-, al menos yuxta modum porque, aparte mi agradecimiento personal, debo a Zubiri, como ya escribí hace años, lo mejor, o al menos lo menos malo, de mi Ética» ${ }^{\perp}$.

Y, ciertamente, un estudio sereno, no sólo de la Ética, sino también de los restantes trabajos de José Luis Aranguren sobre «moral pensada», descubre la nuclear presencia del pensamiento zubiriano, sobre todo de los cursos orales, recogidos más tarde en el volumen Sobre el hombre ${ }^{2}$, que tal influencia ejercieron también en Ios escritos de Pedro Laín Entralgo ${ }^{3}$.

Una tradición de filosofía hispana, en sentido amplio, iba anunciándose así en la obra de estos grandes pensadores, Ortega, Zubiri, Aranguren, Laín. Una tradición, sin duda universal, porque la filosofía «será universal o no

' El Pals, 21-1-1981, citado por F. Blázquez, «Introducción», en J. L. Aranguren, Obras Completas (O. C), Madrid, Trotta, I, 1994, p. 10.

= X. Zubiri, Sobre el hombre, Madrid, Alianza, 1986.

${ }^{3}$ Desde La espera y la esperanza, de 1957 (3. ed en Madrid, Revista de Occidente, 1962), hasta Idea del hombre, Barcelona, Galaxia Gutenberg-Circulo de Lectores, 1996. 
serán, pero pensada, escrita, leída y hablada en español. Hoy la prolongan los miembros del Seminario Xavier Zubiri, muy especialmente Diego Gracia, Antonio Pintor, Antonio Ferraz, Antonio González, Germán Marquínez, Jesús Conill y, por supuesto, el fallecido - asesinado- Ignacio Ellacuría, que extrajo para la liberación de los pueblos oprimidos los beneficios de esta filosofía primera. José Luis Aranguren, por su parte, tomó de ella lo necesario para diseñar por su cuenta y riesgo una ética, en diálogo con las corrientes filosóficas actuales y enriquecida con textos literarios; una ética abierta a la religión y, en su caso, orientadora también de la acción política ${ }^{4}$. ¿Cuáles son los trazos de esa ética, de los que podemos, en el mejor sentido de la palabra, aprovecharnos?

\section{El punto de partida de la moral pensada. Una «ética del carácten}

Ciertamente, en la selección misma del punto de partida de la reflexión se juega una ética gran parte de su andadura. En este sentido, el comienzo habitual de la ética neoescolástica con la que José Luis Aranguren se encontró al iniciar su obra ética era decididamente metafísico. Se trataba de una reflexión sobre el fin último al que todas las actividades humanas se encaminan, sobre el bien que atrae a nuestra voluntad a través de todos los bienes concretos; fin y bien que nos descubre la metafísica, ya que es la causa final de las actividades, las artes y las ciencias. A partir de él cabe proceder de un modo deductivo, extrayendo las orientaciones que del fin último de la conducta humana se siguen para nuestros actos, hábitos y reglas. En tal caso, la ética se subordina a la metafísica, no sólo porque la reflexión descubre al cabo que la moral vivida requiere su concurso para fundamentarse, sino porque el comienzo mismo de la reflexión es ya un capítulo mismo de la metafísica: el referido a la causa final de las acciones humanas.

No es éste, sin duda, el comienzo de la ética de Aranguren, que se acoge a un método circular, hermenéutico, y no deductivo. Ciertamente, la metafísica, o mejor, la filosofía primera, desempeña un papel indispensable en su edificio ético, pero como justificación de los contenidos morales, y no como punto de partida desde el que deducir la realidad moral en su conjunto. La deducción es en esto más construcción dogmática que reflexión sobre la realidad, por eso conviene atender en principio a la realidad misma, que se cxpresa al menos por tres caminos: el etimológico, porque las palabras están preñadas de la realidad a la que convienen; el conocimiento moral vulgar, es decir, lo que

* Para una panorámica del pensamiento de José Luis Aranguren ver E. Bonete, Aranguren: La ética entre la roligión y la politica, Madrid. Tecnos, 1989. Una interesante sintesis es la presentada por H. Carpintero en Cinco aventuras españolas, Madrid, Revista de Occidente, 1967, pp. 109-154. Por su parte, F. Blázquez presenta una excelente biografía de Aranguren en José Luis $L$, Arangurest. Metio siglo de la Historia de España, Madrid, Ethos, 1994. 
las gentes suelen entender por «moral», y, dando un paso más, algún hecho incontrovertible, ante el que tengamos que reconocer hallarnos en un mundo especificamente moral.

Tanto el análisis etimológico como la consideración del conocimiento moral vulgar arrojan en nuestro caso un resultado sumamente fecundo, y es que la moral y la ética se refieren al modo de ser o carácter de las personas, trabajosamente conquistado a lo largo de la vida.

La ética no es primariamente cosa de deberes y normas, ni tiene por tarea calcular utilidades o hacer un panegírico de los derechos humanos. Es lo suyo más bien habérselas con la vita activa, recordando con Hannah Arendt a Aristóteles, percatarse de que los seres humanos nacemos con un talante o temperamento que nos es dado, con un pathos o tono vital que no hemos elegido, y a partir de él vamos labrándonos un carácter moral. Por eso a la ética sólo secundariamente le importan los deberes y las normas, sólo secundariamente le importan los actos concretos. Importa lo que el hombre es, más que lo que hace - apunta también Laín-. Cuando decimos de alguien que «en el fondo es una buena persona», rara vez le retiramos nuestra amistad sean cuales fueren sus actos ${ }^{s}$.

$\mathrm{Ni}$ las normas ni los actos concretos constituyen el interés primero de una ética, preocupada por los infinitivos verbales, por los haceres, más que por los sustantivos, más que por la cristalización en normas, actos o instituciones. $\mathrm{Y}$ es que la vida es quehacer -decia Ortega-y, sobre todo, el quehacer ético es quehacerse ${ }^{6}$.

Hacerse a sí mismo desde el talante recibido, apropiarse de un peculiar carácter, adquirir una segunda naturaleza, es tarea de la que ningún ser humano puede desembarazarse. No somos libres para dejar de ser libres, somos forzosamente morales. Y esta perogrullesca lección, que nos enseñan la etimología de los vocablos «moral» y «ética» y el conocimiento que las gentes tenemos acerca de lo moral y lo ético, recibe de nuevo el espaldarazo de la realidad cuando la consideramos desde la pespectiva quc más importa a José Luis Aranguren: desde la antropológica.

\section{3. ¿Ética material?}

En 1994, en el prólogo a la reedición de su Ética, escrito para el segundo tomo de las Obras Completas, comentaba José Luis Aranguren: «La orientación del libro no era formalista, sino decididamente antropológica. Y el impulso decisivo procedía de Xavier Zubiris?

\footnotetext{
"Pedro Laín, España como problema, 1956, II, p. 508.

- J. L. Aranguren, O. C., II, p. 184.

'J. L. Aranguren, $O . C$., II, p. 161.
} 
Ciertamente, optar por un punto de partida antropológico aleja la construcción de una moral pensada de cualquier factura formalista, al menos de las conocidas. De la lógica trascendental kantiana, del análisis lingüístico y también de la pragmática no empírica defendida por Kark-Otto Apel y Jürgen Habermas desde hace ya más de dos décadas. Frente a este fomalismo de los derechos, los deberes, las normas o el lenguaje, la ética de Aranguren se presenta como una ética material, pero con un «material" que conviene aclarar por no caer en confusiones. Porque repudiar el formalismo, incluso el lógico-trascendental o el pragmático-trascendental, no implica arrojarse en los brazos de cualquier ética material $o$, por decirlo de forma más actualizada, en brazos de cualquier ética sustancialista.

Sabido es que los herederos «directos» de Kant han transmutado el formalismo en procedimentalismo, al reconstruir en clave de diálogo el formalismo kantiano ${ }^{8}$. A la ćtica importan - desde esta perspectiva- los procedimientos a través de los cuales podemos determinar si una norma vigente es o no moralmente correcta, cuando Kant cncomendaba a la ética la tarea de discernir la forma de las máximas que aspiran a acreditarse como leyes morales y la forma de la voluntad que desea ser buena. El procedimentalismo es, pues, un formalismo puesto en diálogo.

Sabido es, por otra parte, que los herederos de algunas éticas materiales de bienes ${ }^{9}$ se dicen «sustancialistas», indicando con ello que les preocupa la naturaleza de la vida buena, to que es bueno ser, y que hacen depender lo correcto de lo bueno ${ }^{10}$. Curiosamente, estos autores incluyen bajo el rótulo «procedimentalismo» no sólo a los mencionados kantianos, sino también a los utilitaristas, por entender que unos y otros comparten una visión procedimental de la ética, como opuesta a una visión «sustantiva».

Una visión sustantiva sería, en principio, la de aquellos filósofos griegos y medievales que tenían a la razón práctica por razón sustantiva: ser racional equivaldría -según ellos- a tener la visión buena, correcta de las cosas. Para los modernos, por contra, relegada la noción del bien, la razón se convierte en razón formal y se despliega en procedimientos, sea en la maximización de utilidades propugnada por los utilitaristas, sea en la universalización defendida por los kantianos. Cierto que entre unos y otros existen diferencias de envergadura, desde el momento en que el utilitarista apuesta por una razón fornal mesológica y calculadora (Zweckrationalität), mientras que el kantiano asume la idea de una razón práctica autónoma, más tarde autónoma y comunicativa. Pero en común tienen el rechazo de una razón práctica sustantiva, para la cual la sabiduría práctica consiste en percibir el orden que, en cierto sentido, está en la naturaleza ${ }^{11}$.

${ }^{8}$ Para la distinción entre éticas materiales y formales y su transmutación en éticas procedimentales y sustancialistas, ver A. Cortina, Etica sin moral, Madrid, Tecnos, 1994, cap. 2.

"No los herederos del hedonismo, como veremos.

'Ch. Taylor, Las fuentes del yo, Barcelona, Paidós, 1996, p. 17.

"Ibid, p. 103. 
Si las cosas son así, parece que la ética de Aranguren será decididamente material y sustancialista, ya que su preocupación central consiste en dilucidar la naturaleza de la vida buena, y encomienda la tarea de discernir entre los bienes que la componen a una inteligencia sentiente, que se despliega en razón desde una originaria compenetración con la realidad.

Nada se construye de espaldas a la realidad. Hacer pie en ella desde el comienzo es indispensable para no acabar manipulândola y tergiversándola, como tan a menudo han hecho los idealismos. En esta aversión hacia el idealismo concuerda Aranguren con el raciovitalismo orteguiano, el reísmo zubiriano y el estructurismo de Pedro Laín ${ }^{12}$. A fin de cuentas consideran los cuatro-, los seres humanos anticipan sus actividades a través de proyectos, a través del pensar, que «pesa», y pesa hacia la realidad de la que se nutre y a la que al cabo regresa tras bosquejar un mundo de irrealidades. El pensamiento tiene que plegarse a la realidad, contar con ella, creer en clla, como Pedro Laín apuntó en La espera y la esperanza.

Por eso la ética ha de ser material y sustancialista en su orientación, en cuanto realista y no idealista; ha de analizar la estructura de la realidad humana para dilucidar, entre otras cosas, cómo es capaz de generar ideas y normas, cómo la inteligencia se despliega en logos y razón. Pero por el orden en que lo hemos mencionado, sin poner la carreta delante de los bueyes ni construir la casa desde el tejado. Otra cosa es que, además de ser material y sustancialista desde esta su versiôn a la estructura de la realidad humana, lo sea tambièn por ofrecer claramente contenidos morales.

Porque ¿qué más dará — puede preguntarse el lector-que la ética de Aranguren sea material o formal, sustancialista o procedimental, si la «moral vivida» en la vida cotidiana no lleva etiquetas? ¿No es este afán de poner rótulos una forma de encorsetar ese discurrir sin membretes de la vida que es el quehacer moral?

Normalmente quienes esto preguntan ponen en su vivir cotidiano bastantes más etiquetas de las que cabría desear, y con bastante menos fundamento del que avala a las distinciones que venimos haciendo. Pero, sobre todo, muestra nuestro preguntador no apercibirse de que con los rótulos nos estamos jugando algo bien importante también para la moral vivida; nada menos que averiguar qué pucde decir la ética cuando intenta orientar la vida corriente.

¿Es capaz la umoral pensada» de indicarnos cuál es la realidad buena y cuál no, dc modo que una persona inteligente deba preferir la primera y rehuir el trato con la segunda? 20 se siente, por el contrario, incapaz de diagnosticar qué realidades son moralmente buenas, incapaz de prescribir -en consecuencia - algunas realidades como buenas urbi et orbe?

${ }^{12}$ Me refiero con la expresión westructurismo», referida a $\mathbf{P}$. Laún, a la posición que remite a la estructura del cuerpo humano, más allá del materialismo y el dualismo, desde El cuerpo humano (Madrid, Espasa-Calpe, 1989), pasando por Cuerpo y alma (Madrid, Espasa-Calpe, 1991), Aima, cuerpo, persona (Barcelona, Galaxia Gutenberg-Circulo de Lectores, 1995) hasta ldea del hombre. 
Una ética sustancialista, en sentido estricto, debería desvelar qué realidades son buenas para cuantos deseen llevar una vida feliz; es decir, para todas las personas. Naturalmente, topará inmediatamente con varios problemas, como puede ser el de la diferente constitución de los sujetos a los que la realidad debe plenificar, o la innegable evolución de los contenidos morales, incluso en el seno mismo de cada cultura, sin necesidad de comparar entre ellas.

Con estos obstáculos se encontró también José Luis Aranguren, y su modo de abordarlos me parece al cabo más expresivo de un nuevo género de ética, situado más allá del formalismo y el sustancialismo tradicionales. En ocasiones se ha referido Diego Gracia a la ética de cuño zubiriano como una «ética formal de bienes», frente a la tradicional «ética formal de deberes» ${ }^{13}$; como -podríamos decir- una "ética formal agathológica», en vez de «formal deontológica» ${ }^{14}$.

Y es posible que lleve razón, pero yo entiendo que a la ética que comentamos, en su versión arangureniana, más convendría el rótulo «ética estructurista», que los tradicionales «material» o «formal», «sustancialista» o «procedimental». Porque su más provechosa oferta consiste - a mi juicio- en el diseño de la estructura de esa peculiar realidad que es el ser humano, en virtud de la cual es necesariamente moral, en un doble sentido: como forzosamente libre, e inevitablemente buscador de la felicidad. El otro lado de lo moral, el del contenido bueno, es a su vez - cn lo que se me alcanzamás objeto de un análisis estructural que sustantivo.

\section{4. Ética estructurista}

«Si he tenido un maestro en filosofía, ese maestro fue Zubiri. Mi mayor deuda, desde ese punto de vista ético, provenía de su distinción entre "moral como estructura" y "moral como contenido"» ${ }^{15}$. Así decía hace pocos años José Luis Aranguren, recordando una aportación zubiriana, tan central para cualquier ética que se precie, que ninguna debería dejar de reflexionar sobre su fecundidad. Porque cualquier propuesta de filosofía moral que desee decir algo valioso para orientar las acciones, se verá obligada a hacer pie en la realidad del comportamiento humano, tal como la desvela una responsable antropología biológica y filosófica.

Extraer las virtualidades para la moral de una tal antropología es tarea en la que empleó Xavier Zubiri alguno de sus cursos orales; pero no es menos cierto - como recuerda Javier Muguerza- que fue José Luis Aranguren quien la dio a conocer en su obra escrita en la década de los cincuenta, y quien

\footnotetext{
${ }^{13}$ D. Gracia, Fundamentos de bioética, Madrid, Eudema, 1988, pp. 369 y ss.

${ }^{14}$ A. Cortina, Ética sin moral, pp. 55 y ss.

${ }^{15}$ Retrato de José Luis L. Aranguren, Barcelona, 1993, p. 78.
} 
la enriqueció con elementos tomados de otras fuentes, hasta construir un sistema de moral pensada ${ }^{16}$.

Acudiendo, pues, a esa antropología común - en principio - a Xavier Zubiri y José Luis Aranguren, una comparación entre la conducta animal y la humana revela que la peculiar estructura del ser humano le fuerza a ser moral ${ }^{17}$.

En efecto, mientras que el animal responde a los estímulos que recibe del medio de forma automática, el organismo humano, en virtud de su formalización externa e interna, queda libre ante los estímulos. La viabilidad de] ser humano exige entonces la aparición de la inteligencia, capaz de hacerse cargo de la situación y de habérselas con las cosas y consigo mismo como realidades, capaz de pergeñar un mundo de posibilidades de respuesta, de entre las que la persona elegirá la que juzgue preferible.

De esta originaria implantación en la realidad extraería Ignacio Ellacuría un imperativo ético, que se articula en tres momentos: hacerse cargo de la realidad, cargar con ella y encargarse de ella para que sea como debe ser. Cosa que puede decirse especialmente de la realidad social, que no es sino la situación humana en la que ya nos encontramos. De ahí que Ellacuría asumiera una filosofía de la liberación como una forma de vida, diseñara una teoría ética comprometida con una realidad deshumanizada, y construyera un modelo de universidad capaz de hacerse cargo de ella, contando en su plan de estudios con una peculiar asignatura: «Realidad nacional» ${ }^{18}$.

Ahora bien, regresando al análisis de la estructura psicobiológica humana, recordemos cómo el ajustamiento al medio que el animal realiza automáticamente recibe el nombre de «justeza», mientras que el ajustamiento que hace el ser humano desde este primer nivel de libertad biológica recibe el nombre de «justificación»; nombre que designa claramente la acción de un sujeto que es el autor, el agente de la misma. La respuesta al medio no me viene dada, sino que tengo que darla, y para ello la inteligencia me lo muestra como una realidad a la que he de responder, como un mundo que de algún modo está en mis manos, y al que tengo diversas posibilidades de ajustarme.

Este primer momento de libertad resulta decisivo al convertir el obrar humano en quehacer: tengo que hacer mi vida, porque no se me da hecha. $Y$ tengo que hacerla ideando posibilidades y eligiendo entre ellas la que juzgo mejor.

El universo de las posibilidades de elección es tan importante como la realidad originaria misma ${ }^{19}$. La capacidad para crear alternativas ante cualquier situación es, a fin de cuentas, la que nos permite ampliar el ámbito de lo real, de tal modo que siempre puede decirse que hay más cera que la que

${ }^{16} \mathrm{~J}$. Muguerza, «El lugar de Zubiri en la filosofía contemporánea», en Del sentido a la realidad, Madrid, Trotta, 1995, p. 26.

1 X. Zubiri, Sobre el hombre, pp. 343 y ss.; J. L. Aranguren, O. C., II, Primera Parte, cap. 7.

'1. I. Ellacuría, El compromiso politico de la filosofia en América Latina, Santafé de Bogotá, El Búho, 1994.

"G. Marquínez, Realidad y posibilidad, Santafé de Bogatá, Editorial Presencia, 1995. 
arde, más caminos que los que parecen dados. Cultivar la inteligencia para saber descubrir senderos nuevos es una obligación psicobiológica, que se modula moralmente si nos percatamos de que nos encamina a la felicidad ${ }^{20}$.

Ahora bien, de entre el conjunto de posibilidades que intelige el ser humano se ye obligado a preferir alguna para conferirle realidad, y a justificar de algún modo su elección.

En esta necesidad de justificar la elección inciden Zubiri y Aranguren como un momento central en el carácter moral de la realidad humana: somos libres de optar por una posibilidad u otra, pero estamos forzados a optar y a justificar nuestra elección.

Aprehensión de las cosas y de mí misma como realidades, libertad ante los estímulos, diseño de posibilidades, necesidad de preferir cuál deseo realizar, justificación de la elegida como la mejor, son elementos de lo que tanto Zubiri como Aranguren han denominado «moral como estructura» o la sestructura moral del hombre» ${ }^{21}$, a diferencia de la «moral como contenido». Sin embargo, todavía restan un conjunto de elementos de esta estructura que conviene recordar. El primero de ellos es el que nos permite, junto con la realidad, iniciar la construcción del sistema: el carácter peculiar de la inteligencia humana, que es ya, desde su origen, sentiente.

\section{La unidad de la persona: inteligencia sentiente}

Situados ya en la realidad, es precisamente la inteligencia la que nos permite captar las cosas y a nosotros mismos como realidades, no como simples estímulos, e inteligir desde ella posibilidades de respuesta al medio que nos provoca. Pero conviene no olvidar que, al hablar aquí de inteligencia, nos estamos refiriendo a una inteligencia sentiente ${ }^{22}$. De nuevo las escisiones practicadas por el idealismo son objeto de un contundente rechazo.

«No hay duda de que todo nuestro conocimiento comienza con la experiencia - había dicho Immanuel Kant-. Pues icómo podría ser despertada a actuar la facultad de conocer sino mediante objetos que afectan a muestros sentidos y que, o bien producen por sí mismos representaciones, o bien ponen

${ }^{20}$ A. Cortina, El quehacer ético, Madrid, Santillana, 1996, caps. 5 y 6.

${ }^{21}$ D. Gracia, por su parte, considera que la «moral como estructura» es más bien «protomoral» (ver Fundamentos de bioética, p. 366). En una línea análoga habla Germán Marquínez, por su parte, de una «protopolitica» en «i Existe en Zubiri una protopolítica?», Diálogo Filosófico, núm. 30 (1994), pp. $377-390$.

22 Curiosamente, la expresión «inteligencia sentiente», que aparece en el primer escrito de la madurez de Zubiri perfectamente datable ( $\alpha$ Sobre el hombrem, 1959, en Siete ensayos de antropología filosófica, Santafé de Bogotá, USTA, 1982, p. 80), fue puesta en curso escrito con anterioridad por Pedro Laín en La espera y la esperanza y por José Luis Aranguren en la Ética de 1958, como propia del pensamiento zubiriano. Ver para todo ello A. Pintor-Ramos, Realidad y sentido, Salamanca, Universidad Pontificia, 1993, p. 95. 
en movimiento la capacidad del entendimiento? ${ }^{23}$. Dos facultades humanas, la capacidad de sentir y la de juzgar, se separaban desde el punto de partida para configurar conjuntamente el conocimiento de experiencia.

$Y$ es esta separación en el origen, que afectarâ no sólo al dualismo «sentir-entender», sino también al «entender-querer», lo que no admite un comienzo antropológico que descubre la naturaleza de la inteligencia humana. La inteligencia humana - afirmarán Zubiri y Aranguren- es constitutivamente sentiente, se hace cargo de la realidad a traves de esa unidad de inteligencia y sentimiento, que no sólo es «vidente», no sólo es capaz de ver, sino es también "posidente», ansiosa de poseer ${ }^{24}$; la complacencia of fruición es una nota esencial de la felicidad, ya que la realidad humana es hedónica, por ser inteligente y sentiente. Intelección y fruición constituyen las dos dimensiones primarias del hombre 25

En términos hodiernos se traduce aquí aquella lúcida visión de Aristóteles, que tiene ya al menos veinticuatro siglos de historia: «la elección es o inteligencia deseosa o deseo inteligente, y esta clase de principio es el hombre» ${ }^{26}$.

El suelo firme desde el que construir el edificio de la ética arangureniana, una ética «con voluntad de sistema» ${ }^{27}$, será, pues, la realidad inteligida en forma sentiente.

\section{Apropiación ética: moral del carácter, moral de las virtudes}

Situada ante la elección entre distintas posibilidades, bien hará una persona en optar por la realmente mejor, porque su elección modificará sin duda la realidad, pero sobre todo modificará su propia realidad, en la medida en que va incorporando, haciendo carne suya, la posibilidad mejor.

En esto consiste en buena medida el quehacer moral, en ir forjando sobre mi «realidad por naturaleza» mi «realidad por apropiación», que es el carácter. «Mi realidad natural — dirá expresivamente Aranguren-es mi propia realidad, en tanto que recibida; mi realidad moral es mi propia realidad, en tanto que

23. Kant, Kritik der reinen Vermunft, B 1 .

${ }^{24}$ J. L. Aranguren, O. C., II, p. 392. Los sentimientos intencionales, cuando verdaderamente lo son, son una modulación de la inteligencia y no de la razón (ibid, p. 352).

"Ibih., II, p. 336. Importa destacar en este punto cốmo José Luis Aranguren percibió en fecha bien temprana -en El protestantismo y la moral (1954)- la relevancia del carácter noérgico del acto de inteligir la realidad, al que Zubiri apuntó en un curso oral sobre filosofía primera en 1952-53. Esta noción resultó decisiva en el desarrollo maduro de la filosofia primera de Zubiri en su versión noológica, y puccé resultar sumamente fecunda para profundizar en las yirtualidades éticas de la inteligencia sentiente. Ver para ello J. L. Aranguren, O. C., II, p. 70. Debo esta importante apreciación a Diego Gracia y Jesús Conill.

* Aristóteles, Ética a Nicómano, Introducción y notas de I. Marías, Madrid, Instituto de Estudios Politicos, $1970, \mathrm{VI}, 2,1139$ b 4-6.

37 I. Aranguren, $O . C .$, II, p. 162. 
apropiada ${ }^{28}$. Una nueva forma de apropiación surge en este contexto, que ninguna relación guarda con el modo jurídico de propiedad, porque se trata en este caso de una apropiación ética.

Quien opta por una acción cargada de solidaridad, precisamente por su valor solidario, va apropiándose de una actitud, de una predisposición a actuar de forma solidaria. Quien opta por una acción insolidaria, porque le parece preferible, va generando en sí mismo la predisposición contraria. Predisposiciones una y otra que reciben en la tradición ética occidental los nombres de virtud y vicio, respectivamente.

La virtud era en el mundo griego - recordemos - la areté, la excelencia del carácter, ligada también a la fuerza para obrar el bien, que acentuarían estoicos, medievales y kantianos. El virtuoso era excelente en una actividad y por eso contaba con la fuerza necesaria para llevarla con bien a cabo. El vicioso, falto de esa fuerza, se veía en dificultades para desarrollar con éxito la misma actividad.

El mundo moderno - como «denuncia» MacIntyre - relegó a un segundo puesto el papel de las virtudes, que de señoras del universo moral pasaron a oficiar de siervas de los deberes o del cálculo. Las virtudes kantianas de La metafísica de las costumbres están al servicio del cumplimiento del deber: constituyen la fuerza del carácter para obedecer la voz del imperativo categórico. La virtud rawlsiana de la justicia es una prediposición cultivada para atender a los principios de la justicia, elegidos en una situación de equidad. La formación discursiva de la voluntad, «virtud» nuclear de la ética discursiva, es indispensable para atenerse al principio ético que ordena tener por correctas sólo las normas que por tales tendrían los afectados a través de un discurso práctico ${ }^{29}$.

Es necesario recuperar la tradición de las virtudes - dirá MacIntyre - para dar carpetazo a la moral del emotivismo en que ha venido a desembocar el mundo moderno. Y, ciertamente, su propuesta de reconstruir la noción de virtud desde las prácticas, desde la unidad de vida y desde las tradiciones, es sumamente sugerente ${ }^{30}$. Sin embargo, recomponer la tradición de las virtudes en las democracias posliberales, como MacIntyre pretende, tiene - a mi juiciosentido si las concebimos como momentos, no sólo de las prácticas, sino de las prácticas como expresión del carácter, sea de las personas, sea de las profesiones o las instituciones ${ }^{31}$.

Por eso una ética del carácter, generado por apropiación, tal como la propone José Luis Aranguren, es en nuestro momento sumamente fecunda, porque señala cómo la unidad vital es no sólo narrativa - que también-, sino resultado de esa tarea de incorporación de las posibilidades mejores, por la que nos

$\therefore$ J. L. Aranguren, O. C., II, p. 217.

${ }^{2}$ A. Cortina, Ética sin moral, cap. 7.

* A. MacIntyre, Tras la wiriud, Barcelona, Critica, 1987, caps. 14 y 15.

${ }^{31}$ P. Arroyo, A. Cortina, M. J. Torralba y J. Zugasti, Ética y legislación en enfermeria, Barcelona, MacGraw-Hill, 1996, cap. 6. 
vamos forjando nuestro propio carácter. En este sentido, contempla cuidadosamente Aranguren un conjunto de virtudes, tomado de diferentes tradiciones ${ }^{32}$.

El gran interrogante que, a pesar de todo, permanece abierto es la pregunta por el bien que conviene preferir con vistas a ir adquiriendo un buen carácter, un êthos capaz de proporcionarnos una vida buena, que es de lo que dicen que debe tratar la ética los defensores de la ética material y detractores del formalismo ético. Porque hasta este momento hemos hablado de «que el ser humano ha de hacerse», no de "lo que ha de hacer, para hacerse bien»; y el estudio de las virtudes nos remite a bien acreditadas tradiciones, pero existen otras tradiciones, y es urgente encontrar el fundamento, la justificación desde la que optar por potenciar unas virtudes u otras.

En este punto entra en juego, con claras reminiscencias aristotélicas, el ineludible atractivo de la felicidad.

\section{Felicidad como estructura}

Para hacerse bien - responderá la ética que comentamos- deberá la persona apropiarse en cada caso de la posibilidad mejor, y en este camino habrá de tener en cuenta que existe una orientación ya sicmpre dada: la oricntación hacia la felicidad.

La felicidad es, a fin de cuentas, la meta última presente en cualquiera de nuestras acciones y elecciones, la que guía nuestras constantes e inevitables apropiaciones. La felicidad no la elegimos, sino que estamos ligados a ella, lo queramos o no.

Ante afirmaciones como éstas sonríen con satisfacción los defensores del sustancialismo ético en sentido estricto, gozosos de contemplar cómo una vez más se confirma su convicción de que todos los seres humanos desean ser felices, como si en alguna ocasión los deontologistas hubieran negado semejante extremo. Han olvidado, al parecer, aquellas palabras de La fundamentación de la metafisica de las costumbres, la obra que dio el espaldarazo al deontologismo en la historia de Occidente: «Hay, sin embargo, un fin que puede presuponerse real en todos los seres racionales (...); hay un propósito que no sólo pueden tener, sino que puede presuponerse con seguridad que todos tienen por una necesidad natural, y éste es el propósito de la felicidad" ${ }^{33}$.

Ciertamente, nadie se ha atrevido a negar verdad tan palmaria como es la de que los seres humanos tienden a la felicidad, a no ser provocadores como Nietzsche que la desprecian al entender que «el ser humano no aspira a la felicidad; sólo el inglés hace eso» ${ }^{34}$. Pero, provocaciones aparte, el problema

32 Ver también A. Pintor, o. c., p. 125, nota 50.

${ }^{3}$ I. Kant, Grundlegung zur Metaphysik der Sitten, IV, p. 415.

${ }^{34}$ F. Nietzsche, El crepúsculo de los idolos, Madrid, Alianza, p. 31. 
no consiste tanto en afirmar o negar que sea la felicidad aquella meta a la que todos tienden, sino en mostrar cuál es el contenido de la felicidad.

Tanto Zubiri como Aranguren responden a la cuestión en principio desvelando su estructura, más que su contenido. La felicidad - dirán- es una de nuestras posibilidades, pero no apropiable, sino ya siempre apropiada, una posibilidad ante la que no cabe elección. Precisamente por eso no puede contraerse a un bien concreto, sea el placer, el bienestar o la vida contemplativa, ni siquiera puede reducirse a una ordenación de bienes. La felicidad se define estructuralmente, en principio, como ula apropiación última de nuestra posibilidad "mejor"; es decir, la "obra del hombre" en sí mismo, la praxis de mi propia realidad ${ }^{35}$.

No es fácil determinar en qué consiste tal praxis, ya que las posibilidades de ser feliz son diversas y por eso a todas ellas conviene el nombre de bienes. De entre los bienes apropiables, sin embargo, algunos, los más conducentes a la felicidad, reciben el nombre de deberes. A ellos estamos obligados a través de su conexión con la felicidad, a la que estamos ya siempre ligados.

La clave de bóveda de este sumamente abierto sistema ético es, pues, la felicidad. A su luz, algunas posibilidades reciben el nombre de bienes, los bienes más conducentes a la felicidad se consideran como deberes, y cobra sentido ir apropiándose de sí mismo al incorporar las virtudes, la segunda naturaleza en que consiste el carácter moral, y que es a fin de cuentas la tarea ética. Una ética estructurista del «carácter y la felicidads es, a mi juicio, el rótulo que mejor convendría a la moral pensada de que tratamos ${ }^{36}$. Pero ¿puede ir más allá y describir el contenido de la felicidad?

\section{El contenido de la felicidad}

Que el ser humano elige atendiendo a lo que le parece mejor, es afirmación que nadie ha puesto en duda, en lo que se me alcanza. Pero lo que considera mejor no tiene por qué ser ya lo moralmente bueno, es decir, lo que conduce a la felicidad. De ahí que la estructura moral del ser humano reclame un contenido moral, una «moral como contenido» que, según Aranguren, procede en principio de los ideales de hombre vigentes en cada época, nacidos - a su vez - de propuestas religiosas, ofertas sociales, situaciones históricas.

Todo ello va generando un bagaje de experiencias con el que cuentan los seres humanos, de forma más o menos consciente, a la hora de optar. Unas - por decirlo con Ortega - funcionarán en forma de creencias; otras, en forma de ideas y proyectos razonados. Pero lo bien cierto es que ése es

${ }_{35}$ J. L. Aranguren, O. C., II, p. 323.

${ }^{36}$ En el número monográfico que la revista Anthropos dedicó a José Lujs Aranguren (múm. 80, 1988, pp. 42-45) me referí a su moral pensada como «Una ética del carácter y la felicidad». Sin embargo, creo que el calificativo uestructurista" viene a especificar inejor su contenido. 
ya un capital del que disponemos, desde el momento en que devenimos personas a través del proceso de socialización, porque - recordemos-incluso la moral personal tiene en su génesis una raíz social. En su génesis, pero no en su fundamento, no en su justificación, porque cada persona puede poner en cuestión los ideales vigentes, y es en esa capacidad para poner en cuestión lo que socialmente le viene dado donde muestra su personalidad moral ${ }^{37}$.

Conviene, pues, acudir a la literatura, la historia, la religión, la política o la sociologia, para descubrir ese bagaje moral del que el tiempo pasado y nuestro propio tiempo nos pertrechan. $Y$ lo primero que llamará nuestra atención sin duda es el hecho inapelable de la evolución de los contenidos morales. Incluso los defensores de la ley natural, como norma adecuada para juzgar acerca de la bondad moral de los contenidos, se encuentran con el problema de que lo único inmutable sean afirmaciones tan formales como «hay que hacer el bien y evitar el mal», o «no hagas a los demás lo que no quieres que te hagan a tis ${ }^{38}$.

No parece, pues, que los detractores del formalismo estén tan lejos de los formalistas; quienes, por su parte, aportan bastante más contenido en virtudes y valores de lo que su presunto formalismo podía llevar a sospechar ${ }^{39}$.

Pero, regresando a la ética de Aranguren, icómo podremos discernir entre los ideales de vida buena que una sociedad ofrece cuál o cuáles merecen ser seguidos? Para averiguarlo es preciso atender al menos a dos polos, estrechamente conectados entre sí: a las tendencias inconclusas de cada ser humano, a las «ferencias" que le inclinan a preferir, y a la bondad misma de la realidad, dotada de un auténtico poder ${ }^{40}$. La inteligencia, como versión a la realidad, proyecta ante cada situación diversas posibilidades, abicrtas por las tendencias, pero es la bondad misma de la realidad la que nos hacc preferir. «En tanto en cuanto el hombre prefiere la realidad buena - dirá Aranguren-, queda justificados ${ }^{41}$.

Este rccurso a la bondad de la realidad para justificar la moralidad de unas preferencias, y no de otras, muestra cómo la moral pensada de que tratamos se abre, más que a una metafísica del ser, a una filosofía primera de corte zubiriano, entendida como saber acerca de la realidad. La filosofía primera, el saber acerca de la realidad, proporciona la justificación que buscábamos al describir la estructura moral del ser humano, ya que la opción por la realidad 106.

${ }^{37}$ J. L. Aranguren, Etica de La felicidad y otras lenguajes, Madrid, Tecnos, 1988, pp. 105 y

${ }^{38}$ J. L. Aranguren, Propuescas morales, en $O . C$, II, p. 590.

* Ver, por ejemplo, la antroponomia que Kant desarrolla en La metafisica de las costumbres, parte II, y la que implícitamente ofrece la ética discursiva, como he intentado mostrar en Ética sin moral cap. 7 .

* Para la relevancia del «pocier de lo real» en la ética que comentamos, en conexión con la nietzscheana *voluntad de poder», ver J. Conill, «Nietzsche y Zubiri», Sistema, núm. 126, 1995, pp. $125-128$.

${ }^{41}$ J. L. Aranguren, O. C., II, p. 208. 
buena justifica que nos apropiemos de unas posibilidades, de aquellas que mejor nos realizan.

Sin embargo, llegados a este punto, no parece José Luis Aranguren verdaderamente satisfecho con este recurso a la realidad, que él mismo, junto con Zubiri, ofrece. Afirmar que la bondad de la realidad es lo que nos hace preferir, no es muy diferente de reconocer que siempre elegimos sub ratione boni, siempre elegimos lo que nos parece mejor. Pero quc algo nos parezca mejor no significa que nos haga felices, porque podemos equivocarnos en la elección, o también preferir un bien más modesto, pero menos costoso. En definitiva, la célebre «debilidad moral» no es tan misteriosa, sino desconocimiento del conjunto de cálculos que una persona ha realizado, consciente o inconscientemente. El fumador empcdernido prefiere «en realidad» -lo sepa él o no- una existencia más corta, pero con tabaco, que una más larga sin él. Otra cosa es que lamentemos su falta de voluntad para dejarlo, por entender que está perdiendo una gran cantidad de posibilidades de disfrute. Pero iquiến se atreverá a "revelar» desde la moral pensada qué posibilidades debemos apropiarnos para llevar una vida digna de ser vivida?

Ortega deja la respuesta a esta cuestión en manos de cada persona, que ha de hacerse a sí misma a través de su vocación y salvando su circunstancia. Esta ética de la fidelidad a sí mismo, que repudia cualquier imperativo universal, genera - por decirlo con Aranguren- un "formalismo de la autenticidad» "2? $\mathrm{Y}$, sin embargo, ¿es que es posible ir más allá del formalismo de los bienes 0 , mejor dicho, de la estructura de la felicidad?

Si extrajéramos de la habermasiana teoría de la evolución social virtualidades que el propio Habermas no extrae, diríamos con él que las sociedades aprenden moralmente, pero añadiríamos - yendo más allá de él - que quien se socializa en una sociedad situada en el nivel posconvencional en el desatrollo de la conciencia moral, no puede tener por «humana» una concepción de la felicidad que no contiene unos mínimos de justicia. Evidentemente, el siguiente paso consistiria en hacer frente a las críticas de cuantos replicaran que tales mínimos no constituyen un componente de su ideal de felicidad, que es el problema central de toda propuesta de felicidad con contenido, siquiera sea un contenido mínimo, siquiera sea axiológico.

No es ésta la opción de José Luis Aranguren, sino la de dar carta de actualidad a aquella tradición que entendía la felicidad como una conjunción de eupraxia y eudaimonía, del buen hacer, cuidadosamente plasmado en el êthos a través de las virtudes, y de la buena suerte, sin la que el mejor proyecto de la inteligencia y la razón fracasa.

La felicidad es buen hacer, como el del zapatero que trabaja el cuero con el que cuenta para sacar de él el mejor partido posible, como el del escultor que golpea la piedra para esculpir una bella estatua. A golpe de cincel vamos haciendo esa «obra del hombre» que es nuestra imagen. $Y$ para que sea lo

J. L. Aranguren, La ética de Onega, O.C., II, p. 531. 
más hermosa posible, vamos aprendiendo de nuestros propios errores y nuestros éxitos, de los errores y los éxitos ajenos, intercambiando opiniones, consejos, recabándolos de la historia pasada y de las culturas distintas a la nuestra. La ética intrasubjetiva precisa, pues, la complementación de una ética intersubjetiva ${ }^{43}$

Contar con la prudencia - aprendemos entonces- es buena cosa, como también lo es contar con un ánimo templado y valeroso. Hacer la justicia en la persona y la ciudad es tarea indispensable, como bien mostró Aranguren en su Ética y política, situada más allá de la órbita de Zubiri, comprometida con la realidad política y social ${ }^{44}$.

Construir un Estado de Justicia es una exigencia ética - decía allí-porque el êthos individual nos lleva al êthos social, la autonomía personal se desarrolla en una «democracia como moral» ${ }^{45}$. Bien que con el tiempo nos hemos percatado de lo indispensable de cse Estado de Justicia, cuando está tan en cuestión el del Bicnestar ${ }^{46}$.

Con todo, la tradición del carácter y las virtudes no alcanza para lograr la felicidad plena, que tanto depende del hacer como de la fortuna. Porque la felicidad es, más que pelagiana, jansenista, es cosa del esfuerzo, del cultivo, pero sobre todo del don. «El don de la paz interior, espiritual, de la conciliación o reconciliación con todo y con todos y, para empezar y terminar, con nosotros mismos" ${ }^{47}$. La felicidad es, al cabo, un regalo que no se conquista, sino que se recibe desde el desprendimiento, la despreocupación y la esperanza.

No es extraño que la ética de Aranguren, volcada a la persona y a su compromiso en la vida sociopolítica, quedara necesariamente abierta a la religión ${ }^{48}$. Porque el don supremo de la felicidad absoluta requiere la silenciosa presencia de un donante que pueda y quiera regalarla.

43 J. L. Aranguren, «Prólogo» a A. Cortina, Ética mínima, Madrid, Tecnos, 1986.

44 J. L. Aranguren, Ética y polficica, Madrid, Guadarrama, 1968.

${ }_{45}$ J. L. Aranguren, "Ëtica comunicativa y democracia», en K. O. Apel, A. Cortina, J. De Zan y D. Michelini, Ética comunicativa y democracia, Barcelona, Crítica, pp. 209-218.

* A. Cortina, «Del Estado del Bienestar al Estado de Justicia», en Claves de Razón Práctica, núm. 41, 1994, pp. 12-20.

47 J. L. Aranguren, Moral de la vida cotidiana, personal y religiosa, O. C., II, p. 720.

45 Para la dimensión creyente de Aranguren ver, por ejemplo, J. Gómez Caffarena, «Catolicismo: lectura y contralectura», en Anthropos, núm. 80, 1988, pp. 58 y 59. 